\title{
o Estado hereditário de Amurru: conspiração, conflitos e traição nas mudanças políticas do domínio Egípcio no século 14 AEC (EA 156-171) ${ }^{1}$
}

\author{
The hereditary state of Amurru: conspiracy, conflicts \\ and betrayal in the political changes of the Egyptian \\ domain in the $14^{\text {th }}$ century AEC (EA 156-171)
}

\section{El Estado hereditario de Amurru: conspiración, conflictos y traición en los cambios políticos del dominio Egipcio en el siglo 14 AEC (EA 156-171)}

\author{
Jovanir Lage
}

\begin{abstract}
RESUMO
Este estudo tem por objetivo abordar a coleção de documentos cuneiformes descobertos no local hoje conhecido como Tell el-Amarna. Tais documentos constituem-se como importante ferramenta arqueológica que preserva informações culturais e históricas da atual Síria e Palestina. As práticas da escrita na Mesopotâmia e o contexto do Crescente Fértil no final da Idade do Bronze compõem os acontecimentos do final da XVIII Dinastia Egípcia no período de maior expansão territorial do Império (1550-1070). A troca de correspondências entre o Grande Rei Amenhotepe IV e seu governante 'Aziru revela as conturbadas relações entre o Império e os Estados sob seu domínio, frente à disputa pelo poder diante da expansão territorial. No estabelecimento do Estado de Amurru, 'Aziru tenta manter as aparências de fidelidade ao Rei, mesmo acusado de conspiração e deserção junto ao Reino Hitita.

Palavras-chave: Tell-el-Amarna; literatura antiga; antigo Oriente-Próximo; dinastia egípcia; Amenhotep IV.
\end{abstract}

\begin{abstract}
This study aims to address the collection of cuneiform documents, discovered in the place now known as Tell el-Amarna. Such documents constitute as important archaeological tool that preserves cultural and historical information of the current Syria and Palestine. The practices of writing in Mesopotamia and the context of the Fertile Crescent at the end of the Bronze Age make up the events of the late 18th Dynasty of Egypt during the period of greatest territorial expansion of the Empire (1550-1070). The exchange of correspondences between the Great King Amenhotep IV and his ruler 'Aziru reveal the troubled relations between the Empire and the states under its rule, in the face of the dispute for power in the face of territorial expansion. In the establishment of the State of Amurru, Aziru tries to maintain the appearances of fidelity to the King, even accused of conspiracy and desertion next to the Hittite Kingdom.

Keywords: Tell-el-Amarna; ancient literature; ancient Near East; Egyptian dynasty; Amenhotep IV.
\end{abstract}

Este artigo é parte da produção de pesquisa realizada durante o ano de 2017 pelo Grupo de Pesquisa "Arqueologia do Antigo Oriente Próximo", da Universidade Metodista de São Paulo - Reg. no CNPq $\mathrm{N}^{\circ} 4338921870858325$. 


\begin{abstract}
RESUMEN
Este estudio tiene por objetivo abordar la colección de documentos cuneiformes, descubiertos en el local hoy conocido como Tell el-Amarna. Tales documentos se constituyen como importante herramienta arqueológica que preserva informaciones culturales e históricas de la actual Siria y Palestina. Las prácticas de la escritura en Mesopotamia y el contexto de la Creciente Fértil al final de la Edad del Bronce componen los acontecimientos del final de la XVIII Dinastía Egipcia en el período de mayor expansión territorial del Imperio (15501070). El intercambio de correspondencia entre el Gran Rey Amenhotepe IV y su gobernante 'Aziru revelan las conturbadas relaciones entre el Imperio y los Estados bajo su dominio, frente a la disputa por el poder ante la expansión territorial. En el establecimiento del Estado de Amurru, 'Aziru intenta mantener las apariencias de fidelidad al Rey, incluso acusado de conspiración y deserción ante el Reino Hitita.

Palabras clave: Tell-el-Amarna; literatura antigua; antiguo Oriente Próximo; dinastía egipcia; Amenhotep IV.
\end{abstract}

\title{
Introdução
}

O período de maior expansão territorial do Império Egípcio (1550 - 1070 a. C.), como propõem John Baines e Jaromír Málek (1996, p. 36), experimentou avanços tecnológicos que ampliaram as relações entre os Faraós e seus governantes. Através de cartas, as relações internacionais eram garantidas por uma linguagem diplomática e informativa. Esta abundante troca de correspondências deixou um valioso conjunto de documentos arqueológicos, que relatam os acontecimentos do final da XVIII Dinastia Egípcia, com foco especial entre os últimos anos do reinado de Amenhotepe III e Amenhotepe IV, conhecido também como Akhenaton. Estes dados nos auxiliam na compreensão de como o Estado mantinha seu domínio diante de tamanha expansão.

A coleção de documentos cuneiformes descobertos no local hoje conhecido como el-Amarna ('Amârnah, cf. RAINEY e SCHNIEDEWIND, 2015, p.xi), é uma importante ferramenta arqueológica que preserva informações culturais e históricas da atual Síria e Palestina e lança luz sobre as práticas da escrita na Mesopotâmia e o contexto do Crescente Fértil no final da Idade do Bronze. Dos 382 tabletes conhecidos, 350 são cartas ou listas que deveriam estar anexadas às cartas e os demais textos referem-se a contos ou relatos mitológicos (MORAN, 1992, P. 17). De todo o conjunto, apenas nove cartas foram "escritas" pelo faraó, sendo todas as outras correspondências recebidas pelos reis egípcios (TAVARES, 2018, p. 3).

O conjunto de cartas que nos propomos estudar neste artigo corresponde à troca de mensagens entre o Grande Rei Amenhotep IV e seu governante 'Aziru, no estabelecimento do Estado hereditário de Amurru (EA 156-171). Ficam expostas, nestas correspondências, as conturbadas relações entre o Império e os Estados sob seu domínio. Amplamente acusado de conspiração por altos funcionários da corte, 'Aziru tenta manter a confiança do Grande Rei, enquanto negocia com o reino Hitita uma possível deserção. 


\section{A abertura/introdução das cartas de El-Amarna ${ }^{2}$}

A maioria das cartas começa com o endereço e a identidade do remetente e do destinatário. Normalmente, o primeiro nome é de posição mais alta. Ao todo, dezenove fórmulas diferentes estão expressas na abertura das cartas, tendo como temas mais comuns: a prostração; a humilhação do remetente; desejo de boa saúde ao destinatário; desejo de boa saúde à casa do destinatário; pedido de bênção e confirmação do envio da carta. Estes temas se revezam, de acordo com a necessidade e a intenção do remetente.

Há três diferentes grupos de cartas, que podem ser classificadas assim:

1) O grande poder (Assíria, Babilônia, Egito, Hatti e Mitanni)

2) Os Estados independentes (Alashia e Arzawa)

3) Os demais (estados vassalos). Nestas, estão presentes as fórmulas de prostração e submissão e pedido de bênção.

A manutenção das relações diplomáticas egípcias passava também pela linguagem. A forma de tratamento comumente utilizada, com termos ligados à família (meu irmão, meu pai), no tratamento mútuo entre governantes e seus subordinados produzia uma ficção de consanguinidade, na qual estas formas protocolares tornavam-se alternativas a uma formulação de caráter sociopolítico. Outra forma de manter estas relações sociopolíticas eram os casamentos diplomáticos.

\section{Referência geográfica das cartas de Amurru}

A área de onde saem as correspondências de Amurru pode ser fechada por um retângulo esquemático que se encontra entre a linha Tripoli-Tartous no oeste, e a linha de Tell Nebi Mend (Qidshu) no leste. Localizado na antiga Síria (agora sul do Líbano), não muito longe de Tiro, este Estado foi governado pelos povos amorreus, que se destacaram em toda a Mesopotâmia, no início do segundo milênio antes de Cristo. O termo "Amurru" tinha sido cunhado pelos acadianos para denotar essas novas pessoas, e passou a ser aplica-

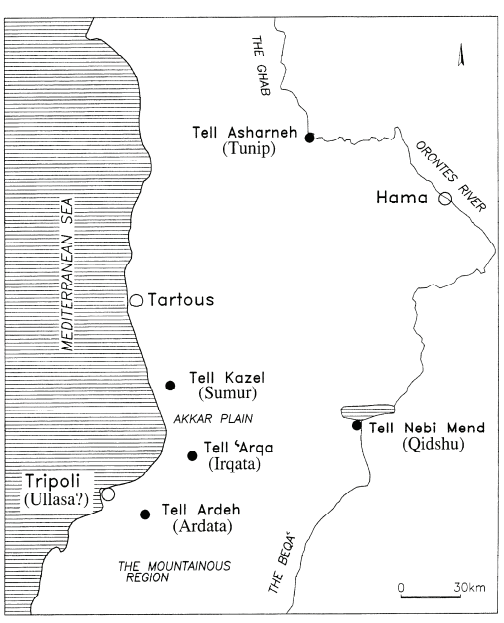
do, em geral, àqueles que permaneceram ao leste da Mesopotâmia.

2 Mais detalhes podem ser encontrados em: MYNAROVA, Jana. A Comment on the Opening Passages of the Amarna Letters - Its Structure and Its Addres. Archiv orienální - Quaterly Journal of African and Asian Studies. Vol. 73 (2005), p.397-406. 
No século 14 A.E.C., o reino estendeu seus limites desde a costa mediterrânea, no norte do Líbano moderno, até as planícies de Homs, na Síria, mas sua história só é conhecida a partir de textos encontrados fora do Estado, nos registros das grandes potências vizinhas, bem como nos textos de Ugarit. A cidade de Damasco era parte dos domínios de Amurru, assim como os portos de Irqata e Sumur.

Ao analisarem a composição química de cada uma das cartas, GOREN, FINKELSTEIN e NA'AMAN (2003, p.3-7), demarcaram o possível local de onde cada uma delas saiu. Este estudo comprova que na investigação petrográfica dos tabletes de Amarna, 15 cartas foram enviadas pelos governantes de Amurru. O território traçado pelos dados obtidos comprova a expansão do reino de Amurru nos dias de Abdi-Ashirta e Aziru.

As cartas de Amurru formam quatro grupos distintos. $\mathrm{O}$ primeiro inclui duas cartas que foram enviadas da área montanhosa a leste de Trípoli, a área central do reino. O segundo inclui quatro cartas, que provavelmente foram despachadas da cidade de Ardata, na encosta montanhosa. Cinco cartas foram enviadas de Tell 'Arqa. Isso parece indicar que depois de consolidar seu reinado, Aziru transferiu sua capital para Irqata, na Planície de Akkar. Finalmente, três das cartas de Aziru foram enviadas do centro egípcio de Sumur. Nenhuma carta de Amurru foi enviada da cidade de Tunip, que também foi capturada por Aziru.

Este estudo nos leva a crer que Irqata serviu como capital de Aziru até o final do Período de Amarna. A carta 170, enviada pelo irmão de Aziru e seu filho, enquanto Aziru estava no Egito, foi despachada desta cidade. EA 161 - provavelmente a última carta de Aziru escrita após seu retorno do Egito e depois de sua conquista de Tunip - também foi enviada de Irqata. De acordo com as cartas, de um modo geral, Irqata funcionava como a sede do exército que protegia o território do reino de Amurru contra um iminente ataque de tropas egípcias (IZRE'EL e SINGER 1990, p. 117-124).

O quadro a seguir mostra-nos, a partir do estudo petrográfico das cartas, sua localização.

\begin{tabular}{|l|l|}
\hline \multicolumn{1}{|c|}{ EA } & \multicolumn{1}{c|}{ LOCALIZAÇÃO } \\
\hline $60 ; 157$ & Montanhas ao leste de Trípoli \\
\hline $61 ; 62 ; 156 ; 159$ & Ardata \\
\hline $100 ; 161 ; 164 ; 169 ; 17 ; 171$ & Irqata \\
\hline $165 ; 166 ; 167$ & Sumur \\
\hline 168 & Gaza \\
\hline
\end{tabular}

Tabela 1. Petrografia do grupo de cartas de Amurru*

* Veja o quadro completo em: GOREN, Yuval, FINKELSTEIN, Israel, NAAMAN, Nadav.The Expansion of the Kingdon of Amurru According to the Petrographic Investigation of the Amarna Tablets. Basor 329, 2003. p. 4 


\section{O Estado hereditário de Amurru}

Quase setenta cartas na coleção de Amarna são de Byblos (Gubla, conhecida hoje pelo seu nome árabe Jubail), situada na costa do mar Mediterrâneo, cerca de $32 \mathrm{~km}$ ao norte de Beirute. A maioria delas é de Rib-Haddi, regente de Byblos. A partir de evidências internas, os textos podem ser divididos em dois grupos, o primeiro datando do reinado de Amenotep III e o segundo até o tempo de Amenotep IV. Em ambos os casos, Rib-Haddi está tentando alertar o rei egípcio e seus ministros sobre o avanço dos 'apîrus, perigo iminente para os interesses do território egípcio.

Durante o curso dos acontecimentos refletidos em sua correspondência, podem-se rastrear as mudanças na política egípcia que, finalmente, sob Amenotep IV, resultou no estabelecimento do estado hereditário de Amurru e sua posterior apostasia ao rei dos hititas, Suppiluliuma. Amurru era um reino amorreu, composto por nômades que viviam nas áreas das montanhas do Líbano e na costa onde estavam as grandes cidades comerciais como Beruta (Beirute), Gubler (Biblos), Ardata, Ullassa, Irqata, Sumur e outras. A última, Sumur, era a residência do governador egípcio no país.

O primeiro inimigo dos interesses egípcios era um homem de ascendência ou origem não identificada (provavelmente nômade), 'Abdi-Ashirta. Portador de um nome claramente semita, foi governante de Amurru. Durante seu governo, Amurru era uma "terra descentralizada", que consistia em vários sistemas políticos independentes. Consequentemente, embora Abdi-Ashirta tivesse influência entre esses sistemas, ele não os governava diretamente (BENZ, 2016. p. 141-166). Rib-Haddi reclamou amargamente ao faraó Akhenaton das tentativas de Abdi-Ashirta em alterar o cenário político às custas da expansão (MORAN, 1992. p. xxiii). A morte de Abdi-Ashirta é mencionada na EA 101 por Rib-Haddi em uma carta para Akhenaton (MORAN, 1992. p. 174). Para descontentamento de Rib-Haddi, Abdi-Ashirta foi sucedido por 'Aziru, seu filho. Este, mais tarde, iria capturar, exilar e provavelmente matar Rib-Haddi.

Como governante principal de Amurru, 'Aziru é acusado de manter negociações com os povos de Ardata. Denunciado por Hib-Haddi', o novo governante é convidado a comparecer perante o rei, mas para ganhar tempo oferece seus filhos em troca de sua permanência em Amurru. Suas primeiras cartas expressam a preocupação em manter a confiança do Rei e evitar ao máximo a viagem ao Egito. 


\section{EA $156^{3}$}

(1-3) Ao rei, meu senhor, meu deus, meu deus sol; a mensagem de 'Aziru, seu Servo: sete vezes e sete vezes aos pés de meu senhor caí.

(4-8) Agora, quanto ao pedido que o rei, meu senhor, tem feito, eu sou teu servo para sempre e meus filhos são teus servos.

(9-14) Agora, dois rapazes tenho dado, a saber, meus filhos. Assim, podem eles levar a cabo [tudo] o que o meu senhor ordenar. Mas pode [meu senhor] me deixar na terra de Amurru.

A composição mineral desta carta é muito parecida com EA 61 e EA 62, escritas por 'Abdi-Ashirta. Sua semelhança material indica que ambas pertencem à mesma região de Ardata (cf. Tabela 1). O cabeçalho também é muito semelhante. $\mathrm{O}$ autor se coloca como aquele que cai sete vezes aos pés de seu Senhor, sinalizando de forma diplomática sua submissão e fidelidade ao rei (1-3); reafirma sua submissão (4-8) e tenta desviar-se das suspeitas levantadas contra ele e envia seus dois filhos ao Faraó, como relação de troca para continuar em Amurru.

Parece que Tutu, ministro-chefe, e alguns outros altos funcionários egípcios chegaram à conclusão de que serviria os melhores interesses do Egito se 'Aziru e seus irmãos pudessem estabelecer um Estado de contenção na fronteira norte de Canaã. Se, por um lado, as forças de Suppiluliuma estavam fazendo sua presença sentida no norte da Síria, por outro, um estado de amortecimento de Amurru controlaria a planície bifurcada pelo Nahr el-Kebîr e também a passagem entre as montanhas libanesas e Jebel Anșariyeh; ou seja, o corredor que liga a costa mediterrânea à Síria central.

O controle dessa passagem poderia permitir que 'Aziru adquirisse vastas somas de direitos alfandegários do lucrativo comércio de caravanas. Assim, 'Aziru prometeu ao rei e Tutu (e provavelmente outros oficiais) compartilhar os benefícios.

Em carta direcionada ao Ministro-chefe Tutu (EA 158), indicando tratamento de consanguinidade diplomática ("meu pai”, "seu filho”), 'Aziru reafirma sua lealdade e servidão ao rei, prometendo continuidade (5-9), mas tenta garantir o apoio de Tutu perante o rei e, para isso, oferece-se para servi-lo da mesma forma (10-13). De maneira bastante sutil, 'Aziru, revelando cumplicidade de laços familiares, tenta "subornar" Tutu em troca de seus favores perante o rei (14-19); pede que ele não permita que falem mal dele perante o rei (20-31), prevenindo-se de cartas já enviadas por outros governantes como Rib-Haddi e Ilirapi', anunciando suas negociações para assumir o controle de Beq'a (EA 139, EA140).

3 Todas as traduções dos textos aqui apresentados foram realizadas a partir dos textos em inglês (MORAN, 2004; RAINEY, 2015), priorizando as opções do texto crítico mais reconhecido de Rainey (2015). 
Vejamos a tradução:

\section{EA 158}

(1-4) Para Tutu, meu senhor, meu pai; a mensagem de Aziru, seu filho, seu servo: Aos pés de meu senhor caí. Que esteja bem com o meu pai.

(5-9) Tutu, agora eu tenho fornecido o pedido do rei meu senhor, e qualquer que seja a solicitação do rei, meu senhor, que ele escreva e eu vou suprir.

(10-13) Além disso, olha, você é meu pai lá (ali) e qualquer que seja o pedido de Tutu, meu pai, escreva e eu realmente desejarei fornecer.

(14-19) Olha, você é meu pai e meu senhor e eu sou seu filho. Os territórios de Amurru são seus territórios e minha casa é sua casa. E qualquer que seja o seu pedido, escreva para mim e eu realmente suprirei todos os seus pedidos.

(20-26) E olha, você permanece na presença do rei, meu senhor. Certamente homens mentirosos falariam uma palavra falsa contra mim na presença do rei, meu senhor. Mas você não deve permitir.

(27-31) Eis que vós [...] estais na presença [do rei], meu senhor representando-me [que] não deveis permitir palavras mentirosas contra mim.

(32-35) E eu sou o servo do rei, meu senhor, e das palavras do rei, meu senhor, e das palavras de Tutu, meu pai, nunca vou me afastar.

(36-38) Portanto, se o rei não ama, mas me odeia o que posso dizer?

As estratégias de 'Aziru para se preservar diante do rei contam agora com investidas diretas em seu ministro chefe, Tutu. 'Aziru sabe da importância de ter aliados junto ao rei e, por isso, tenta influenciá-lo com garantias de prover-lhe de tratamentos equivalentes ao rei, garantindo-lhe parte do território de Amurru e os benefícios de sua casa. Em contrapartida, 'Aziru pede sua proteção junto ao rei, diante das constantes denúncias a seu respeito.

'Aziru, na verdade, continuava promovendo as ações de seu pai, 'Abdi-Ashirta, em negociações com o rei de Mittani para tomar as cidades até Sumur (EA 104: 6-54). Mas sua estratégia é continuar mantendo a aparência de fidelidade e serviço ao rei para ganhar tempo. Os elogios e presentes (tributos) servem como moeda de troca neste sistema. Alega atender ao pedido do Rei, reconstruindo a cidade de Sumur, mas, entre uma afirmação e outra, tece elogios e envia presentes, esperando convencer o rei de sua lealdade (EA 159).

Ao que tudo indica, Yanhamu, um alto funcionário do governo, foi de perto ver a situação no campo e colocou 'Aziru em grande desconfiança. Talvez, a influência de Yanḥamu levou ao "convite" a "Aziru para visitar o Egito. 'Aziru expressa sua ânsia de servir ao rei, mas relata que Yanḥamu não o permitiu. A afirmação de que ele deteve seus enviados que estavam no caminho para o rei tenta passar descrédito sobre a fidelidade de Yanḥamu. 


\section{EA 171}

(3-13) Anteriormente, eu queria entrar em servidão para o rei, o deus do sol, meu senhor, mas Yanḥamu não me permitia. Então enviei os meus mensageiros ao rei, meu senhor, mas Yanḥamu os deteve na estrada e eles não puderam sair. Então, os deuses do rei, meu senhor, concederam que meus enviados saíssem da mão de Yanhamu. Eu entrei na servidão do rei, o deus, o deus do sol, meu senhor mas Yanḥamu não me permitiu.

Quando chegou no Egito, 'Aziru recebeu uma carta de seu irmão, Ba'luya e seu filho, Bêti-'ilu, informando-o de uma invasão hitita da terra de 'Amqi e também da chegada informada de um grande exército na Síria central, liderado por Zitana, irmão de Suppiluliuma (EA170). Eles também escreveram ao rei e a Tutu (EA169: 12-34).

A família de Aziru pagou um resgate pela sua libertação, pois afirmavam que sua presença era necessária em Amurru para proteger os interesses do Egito em face da ameaça hitita. Quando foi libertado, 'Aziru imediatamente começou a tomar medidas para sua eventual deserção para Suppiluliuma. Então, o faraó, desconfiado, exortou Aziru a retornar (EA165), mas ele continuou a adiar seu retorno com o pretexto da ameaça hitita.

(28-41) Senhor, não tome nada em seu coração. Estou indo. Minha preocupação é o rei da terra de Hatti, mas agora estou vindo para ver a face do deus do sol, meu senhor. Meu senhor, eu estou localizado na cidade de Tunip e o rei da terra de Huatti está vindo para a terra de Amurru, a terra do rei, meu senhor. Se o rei, meu senhor, me permitisse guardar a sua terra. Mas agora ele (o rei de Hatti) está localizado em Nuǵasse, duas marchas de um dia de Tunip e eu tenho medo de seu ataque à cidade de Tunip. Ele pode partir!

Em resposta às exigências do faraó de que ele se apresentasse (de novo) ao rei no Egito, 'Aziru argumenta que Suppiluliuma estava perto demais e que ele ostensivamente queria proteger o território controlado pelo Egito (EA 166: 21-29).

(21-29) O rei da terra de Hatti está situado na terra de Nuǵasse e tenho medo dele, caso ele possa me levar para a terra de Amurru. E se ele atacou a cidade de Tunip, são apenas duas marchas do dia do lugar onde ele está localizado. Então eu tenho medo dele e por causa disso, estou de pé até sua partida.

O que ele realmente fez está escrito no preâmbulo do tratado entre ele e Suppiluliuma:

'Aziru, o rei de [Amurru] abandonou o portão do Egito e tornou-se sub-servo do Sol, o ki [ng de Huat] ti. E o Sol, o grande rei, se alegrava [...] que Aziru caiu aos pés do Sol. 
Ele ('Aziru) veio do portão do Egito e caiu aos pés do sol. Eu, o Sol, o grande rei, [recebemos] 'Aziru e eu adicionamos ele aos seus colegas... (Versão hitita, I, 23-26; Singer 1990: 146-147. Cf. RAINEY, 2015. p. 21)

Enquanto isso, o desafortunado Rib-Haddi, cujas mensagens e serviços eram ignorados pelo faraó, foi forçado a abandonar a sua cidade por causa de seu irmão:

Além disso, eu mesmo fui a 'Ammunīra e meu irmão, mais novo que eu, alienou a cidade de Byblos para dar a cidade aos filhos de 'Abdi-Ashirta, porque meu irmão viu que meu embaixador saiu de mãos vazias, não havendo tropas de guarnição com ele, e ele me insultava. E assim a traição foi cometida e ele me expulsou da cidade. Que o rei, meu senhor, não fique em silêncio sobre os feitos deste cão! (EA137: 14-26)

Ele buscou asilo em Beirute, onde um novo governante, 'Ammunīri, recebeu-o de má vontade (EA 142: 15-24). Mais tarde, ele chegou até 'Aziru para tentar fazer um pacto (EA 162: 2-4), porém, em Sidon, 'Aziru entregou-o aos governantes locais, que presumivelmente o mataram (EA 162: 12-14). O rei escreve a 'Aziru questionando os acontecimentos que envolveram Hib-Haddi e seu irmão Ilirapi'.

\section{EA 162}

(1-6) Fala a Aziru, governador da cidade de Amurru: Assim diz o rei, vosso senhor: O governador da cidade de Byblos vos falou aquele a quem seu irmão lançou da porta, dizendo: "Leve-me e me leve de volta à minha cidade. Há muita prata e eu irei lhe dar. Observe, há muitas riquezas, mas não há nenhuma comigo”. Ele falou assim com você.

Aos poucos, Amurru vai convertendo-se em um Estado vassalo do Império Hitita (com alguns períodos de deserção) (IZRE’EL e SINGER, 1990, p.155-160). A resposta egípcia se dá com o planejamento de uma campanha militar (IZRE'EL e SINGER, p.163).

\section{Considerações finais}

Embora formem um corpus pequeno de documentação, o exame das informações contidas nas Cartas de Amarna, nos dão boas impressões sobre a situação política da região da Síria-Palestina durante o final da XVIII Dinastia Egípcia. Fica claro uma reavaliação política de Amurru, frente à guerra entre o Egito e o Reino Hitita. Tais documentos nos mostram que a diplomacia era essencial para manter os territórios e os aliados conquistados. Por outro lado, esta pseudo-hegemonia mantinha-se conservada por meio de diferentes fatores, como os casamentos diplomáticos e a troca de presentes. Não sabemos ao certo a quantidade de tabletes que se perdeu, dada sua fragilidade 
e a maneira como foram descobertos - segundo alguns relatos, por uma camponesa que vasculhava as ruínas em busca de fertilizante agrícola -, mas os documentos existentes mostram a instabilidade do Império Egípcio e o esforço do governo para manter suas relações com os aliados.

A mudança para os Hititas foi um processo gradual desenvolvido por 'Aziru (IZRE'EL e SINGER, p.181). As cartas indicam claramente que os Egípcios, através de sua expansão, estavam planejando uma operação militar em grande escala rumo à Síria. 'Aziru e seus novos soberanos tinham todas as razões para empreender medidas preventivas que pudessem conter o avanço Egípcio pelas costas da Fenícia.

A possibilidade de compreender, portanto, os meandros da administração Egípcia e os conflitos que marcaram a história desta região, torna-se importante ferramenta para a reconstrução do cenário histórico, político e comercial da Síria e Palestina.

\section{Referências bibliográficas}

BAINES, John; MÁLEK, Jaromir. O mundo egípcio: deuses, templos e faraós. Madrid: Ediciones del Prado, 1996. v.1.

BENZ, Brendon C. The land before the kingdom of Israel: a history of the southern Levant and the people who populated it. Winona Lake, Indiana: Eisenbrauns, 2016, p. 141-166.

GOREN, Yuval; FINKELSTEIN, Israel; NAAMAN, Nadav. The expansion of the kingdon of Amurru according to the petrographic investigation of the Amarna tablets. Basor 329, 2003.

IZRE'EL, Shlomo; SINGER, Itamar. The general's letter from Ugarit. a linguistic and historical reevaluation of RS 20.33 (Ugaritica V, No. 20). Tel Aviv: Tel Aviv University, 1990.

MORAN, W. L. The Amarna letters. Baltimore: Johns Hopkins, 1992.

MYNAROVA, Jana. A comment on the opening passages of the Amarna letters: its structure and its address. Archiv orienální- Quaterly Journal of African and Asian Studies. Vol. 73, 2005.

RAINEY, A. (SCHNIEDEWIND, W.; COCHAVI-RAINEY, Z. (eds.)). The El-Amarna Correspondence: a new edition of the cuneiform letters from the site of El-Amarna based on collations of all extant tablers. Leiden; Boston: Brill, 2015.

TAVARES, Irene Alexandra Semião. Guerra e diplomacia no Império Novo: análise dos aspectos militares presentes nas Cartas de Amarna. Portugal: Dissertação de Mestrado em História Militar, Universidade de Lisboa - Faculdade de Letras, 2018.

Submetido em: 3-5-2018

Aceito em: 24-5-2018 